\title{
O VIAJANTE ESPERADO: A ATUAÇÃO DO ASSISTENTE SOCIAL COM ADOLESCENTES
}

\author{
THE TRAVELER EXPECTED: THE ACTION OF SOCIAL WORKER WITH \\ TEENAGERS
}

Elaine Cristina Silva ${ }^{1}$

\begin{abstract}
RESUMO
Os jovens representam uma parcela importante da população nacional e sofrem as consequências econômicas, políticas e sociais do país. Considerando as intervenções dos assistentes sociais com adolescentes e suas famílias em um serviço de saúde, analisamos a prática profissional com base no pressuposto de que a orientação e o acompanhamento são ações socioeductivas e podem contribuir para a emancipação ou manipulação desses usuários.
\end{abstract}

PALAVRAS-CHAVE: Serviço Social. Ações Socioeducativas. Saúde. Adolescentes.

\begin{abstract}
Young people represent an important share of the national population and suffer the consequences economic, political and social the country. Considering the interventions by social workers with adolescents and their families in a health service, we analyze the professional practice based on the presupposed that the guidance and monitoring are actions socioeductivas and can contribute to the emancipation or manipulation of these users.
\end{abstract}

KEYWORDS: Social Work. Actions Socioeductivas, Health. Teens.

\section{O CARÁTER EDUCATIVO NA ATUAÇÃO DO ASSISTENTE SOCIAL}

Para os assistentes sociais que atuam diretamente com os usuários nos serviços de saúde é recorrente a procura por acolhimento, escuta e orientação, somando-se ao desejo explícito ou implícito de resolução de uma situação de falta de acesso a recursos ou serviços, bem como, situações de sofrimento. Neste contexto as ações podem ganhar uma conotação menos importante no rol de procedimentos executados pelos demais

\footnotetext{
${ }^{1}$ Graduação em Serviço Social pela Faculdade Paulista de Serviço Social, SP e Mestre pelo Programa de Estudos Pós-Graduados da PUC/SP. Pós-Graduações Lato Sensu em Serviço Social: direitos sociais e competências profissionais (UnB-CEAD, CFESS, ABEPSS - 2010). E-mail:

elainecsilvapv@gmail.com.erv.

Soc. \& Saúde, Campinas, SP v. 12, n 1 (15), p. 83-102 jan./jun. 2013 ISSN 1676-6806
} 
profissionais que compõem os serviços de saúde, essa é uma avaliação realizada até mesmo pelos assistentes sociais. Todavia, entendemos que estas ações encerram possibilidades contraditórias, sendo bem mais relevantes do que à primeira vista possam demonstrar. Nelas estão contidas as possibilidades de ações educativas, disciplinadoras ou emancipatórias. Com esta compreensão propomos apresentar as colaborações dos intelectuais da categoria, como: Iamamoto (2009, 2009a), Yazbek (2003, 2009) e Mioto (2009) para discutir os limites destas duas direções possíveis na atuação.

O assistente social desenvolve um "trabalho complexo" - conforme Iamamoto fazendo parte de um “coletivo de trabalhadores”, cujo resultado é um trabalho cooperativo. Essa ação na área da saúde tem um peso singular - pelo caráter dos serviços e demandas que mobilizam os usuários - fazendo com que o recorte da “questão social” trabalhada pelo profissional exija a comunicação com outros profissionais - dentro e fora da instituição - e serviços. Ou seja, ações socioassistenciais, que ganham uma dimensão socioeducativa quando viabiliza “o acesso aos direitos sociais”, bem como "os meios para exercê-los” (IAMAMOTO, 2009, p. 354).

O acesso ao direito ultrapassa a abordagem individual - mesmo sendo realizada com um indivíduo ou família nos limites institucionais - na medida em incentiva este usuário a problematizar essas necessidades exigindo respostas coletivas para superação de situações que comumente são fragmentadas e se escondem no interior das "casas pobres”, das “famílias pobres” e das “pessoas pobres”. Dar visibilidade para essas situações, mobilizar a rede de serviços, demonstrar que as estratégias de fragmentação e individualização da questão social além de perversa, é inútil, é também uma ação profissional que afirma o compromisso da categoria com a construção de outra ordem social. Desta forma, o educativo extrapola aquele indivíduo, alcança as relações sociais que este estabelece na sua realidade local, por conseguinte, tem um horizonte emancipatório.

Seguindo com as contribuições de Iamamoto, dentre as ações que o assistente social desenvolve no atendimento direto ao usuário, destacamos a socialização de informações, que:

[...] não se reduz ao mero repasse de dados sobre as normas e recursos legais; é uma informação transmitida na ótica do direito social, em que os sujeitos individuais e coletivos são reconhecidos em suas necessidades coletivas e demandas legítimas, considerando a realidade macrossocial de que eles são parte e expressão (IAMAMOTO, 2009a, p. 356). 
Socializar as informações neste sentido, não se trata do repasse de dados, muitas vezes obsoletos. Antes, trata-se de uma ação refletida, que mobiliza - profissional e usuário - na busca de informações, conhecimentos e respostas que ultrapassem o momento emergencial. O horizonte é a comunicação que viabilize nova postura e ações diante das situações vividas cotidianamente, bem como, a intercomunicação de profissionais, serviços e políticas no atendimento às necessidades sociais de indivíduos inteiros, que merecem um atendimento digno. Assim, não cabe utilizar o setor de Serviço Social como um "balcão especializado de informações”. O usuário espera do assistente social muito mais. Essa ressalva emerge da nossa experiência empírica. De fato, um número expressivo de usuários é orientado a procurar, erroneamente, o setor quer por funcionários ou profissionais do Pronto Atendimento Adulto como de outros serviços municipais. Este movimento tende a dificultar a intervenção profissional, posto que, limita o acesso do usuário ao atendimento desejado e/ou necessário, e, por vezes exige do usuário gastos com transporte.

Yazbek (2009) entende que a atuação do assistente social se dá tanto "pelo atendimento de demandas e necessidades sociais", com diferentes impactos, como, "por uma ação socioeducativa [...], interferindo em seus comportamentos e valores, em seu modo de viver e de pensar” (YAZBEK, 2009, p. 135). Entendemos que as contribuições de Yazbek, não divergem de Iamamoto, ainda que separe em dois momentos, uma ação que para nós é simultânea, ou seja, ao viabilizar o acesso aos serviços, programas e benefícios, o profissional também produz mudanças no comportamento destes usuários. Essa ação pode ter duas conotações contraditórias: o enquadramento ou o fortalecimento das lutas sociais.

Mioto (2009) comunga com as autoras já mencionadas, mas se destaca por vincular ações de orientação e acompanhamento, ao caráter educativo da profissão. A autora considerando as contribuições de Abreu (2002) destaca a compreensão de que as ações direcionadas a indivíduos, famílias e grupos, estão vinculadas ao caráter educativo da profissão, pois se alicerçam no reconhecimento de que “[...] as atividades desenvolvidas pelos assistentes sociais têm uma 'função pedagógica' [...]”, podendo ser identificadas na relação dos profissionais com as classes subalternas. Assim, diante da 
elaboração do projeto profissional emerge uma "pedagogia emancipatória”, com a proposta de "subverter a maneira de pensar e de agir dos homens enquanto totalidade histórica e assim subverter a ordem intelectual e moral estabelecida no capitalismo” (MIOTO, 2009, p. 499). Nesta linha de análise, tanto a orientação como o acompanhamento são abordados enquanto ações socioeducativas, tanto pelo seu caráter educativo, como pela interferência que realiza na vida dos usuários atendidos pelos assistentes sociais. Ao discutir o caráter educativo nas ações de orientação e acompanhamento, Mioto (2009), destaca que estas estão vinculadas a “[...] a três grandes processos de articulação das ações profissionais que são os processos políticoorganizativos, processos de planejamento e gestão e os processos socioassistenciais” (2009):

Considera-se que a orientação e o acompanhamento, tradicionalmente vinculados ao atendimento de demandas singulares de indivíduos, grupos e famílias, configuram-se como ações socioeducativas que se desenvolvem nos processos socioassistenciais e que se articulam organicamente com os processos de planejamento e gestão e com os processos políticoorganizativos (MIOTO, 2009, p. 500)

Optamos por abordar mais detalhadamente os processos socioassistenciais por encontrar comunicação com a nossa realidade empírica o que possibilita o reconhecimento de que as possíveis ações norteadas por uma "pedagogia emancipatória” estão presentes, sobretudo, na “suposta” indefinição de atribuições e/ou na falta de protocolos fechado. Todavia, é certo que tais processos abrem margem para as abordagens centradas no indivíduo em si mesmo, e assim, abortam - entre outras - as possibilidades de socialização de informações e de processos reflexivos, dois pilares das ações socioeducativas no âmbito dos processos socioassistenciais. Acrescentando elementos sobre a socialização de informações - uma ação muito requisitada pelos usuários e profissionais ao assistente social - Mioto (2009) compartilha com as contribuições de Iamamoto (2009) destacando a relação existente entre a socialização de informações e a cidadania, bem como o aspecto legal desta ação na visão de outros autores:

Cepik (2000) classifica o direito à informação como um direito civil, político e social e destaca a sua centralidade para a construção da cidadania contemporânea. Para o autor a socialização da informação constitui-se, por um lado, como uma pré-condição para a incorporação plena de indivíduos e sujeitos coletivos, de forma organizada e qualificada, aos processos decisórios. Por outro, instaura a possibilidade de uma efetiva 
contraposição à lógica das grandes organizações, sejam elas estatais ou empresariais. Assim, ela constrói possibilidades de ajudar a qualificar a relação entre "sujeitos autônomos numa esfera pública reconstruída” (CEPIK, 2000, p. 12, In: MIOTO, 2009, p. 502).

Mioto acrescenta contribuições de Silva (2000), apontando a relação desta ação com os direitos e como uma “alternativa para a ‘tradicional orientação’ vinculada à normatividade legal e ao enquadramento institucional dos usuários” A socialização de informações na lógica do direito, visa à promoção de processos de politização, partindo da concepção de indivíduos como sujeitos de direitos. (SILVA, 2000, p. 124, In: MIOTO, 2009, p. 502). Informar para garantir que os usuários possam usufruir “[...] de todo conhecimento socialmente produzido, especialmente daqueles gerados no campo da ciência e da tecnologia [...]”, de modo que sejam compreensivas, para que os usuários dele façam uso nos diferentes momentos da sua vida.

No ambiente hospitalar o acesso à informação é um ponto bastante delicado, dentre outros, pelos seguintes motivos:

- o uso de termos técnicos utilizados sobretudos por médicos, dificulta a compreensão e tende a resultar no não cumprimento das orientações;

- a rotina intensa que exige dos profissionais uma maior atenção para salvar vidas, por vezes coloca em segundo plano a atenção ao diálogo, gerando muita ansiedade e revolta;

- há informações que são prerrogativas médicas e não podem ser transmitidas por outros profissionais. Este aspecto é muito pouco compreendido pelos usuários;

- pela dinâmica do serviço, em muitas situações processos administrativos são alterados e não são informados para os diferentes funcionários e profissionais, esta lacuna resulta em orientações equivocadas.

Neste contexto, os assistentes sociais são demandados para "solucionar" situações conflituosas, contribuir na compreensão da informação e, raras vezes, para construir fluxos de informação. De acordo com a situação o profissional tem a oportunidade de informar e refletir com o usuário acerca da situação e assim desenvolver estratégias para o atendimento da demanda apresentada. Nesta perspectiva, as demandas dos usuários não são identificadas como "problemas" que merecem 
intervenções pontuais. Ao contrário, o usuário é identificado como sujeito de direitos que apresenta demandas que sendo vividas individualmente, fazem parte das relações sociais, ou seja, dizem respeito à sociedade.

O segundo pilar da ação socioeducativa é o processo reflexivo que exige três elementos: escuta, diálogo e problematização. Neste tripé está presente as contribuições do pensamento de Paulo Freire para uma importante parcela de assistentes sociais (MIOTO, 2009, p. 503).

O processo reflexivo exige uma escuta atenta para que o profissional possa identificar os elementos explícitos e implícitos da demanda, o que não se trata de verificar a veracidade das informações, mas sim de colocar em pauta aspectos da situação que permita a construção de um diálogo respeitoso e uma problematização construtiva.

Por vezes o usuário procura o setor de Serviço Social e “exige” a solução para uma situação que não tem relação imediata com o Pronto Socorro - pela natureza do serviço -, mas esta relaciona e exige a articulação dos serviços de Atenção Básica (no âmbito da saúde, habitação, assistência social). São situações mantidas por longo tempo, mas que chegaram a um ponto insustentável. Entendemos que se trata de um movimento realizado pelo usuário, como parte de uma estratégia de explicação de uma determinada situação, para o profissional e para si mesmo. O usuário espera que o profissional entenda o que ele está dizendo e aponte os caminhos para uma solução. Nestas situações, o cumprimento do processo reflexivo depende de múltiplos fatores e pode convergir com outras ações como: contatos telefônicos, encaminhamentos e elaboração de relatórios.

Entendemos que a proposta de refletir sobre as possibilidades das ações de orientação e de acompanhamento aos adolescentes e seus familiares, a partir da concepção até aqui trabalhada - enquanto ações socioeducativas apoiadas na socialização de informações e em processos reflexivos - não é uma tarefa simples e exige a consideração de dois pontos:

- A natureza dos serviços: rotina, espaço físico, demandas apresentadas;

- As especificidades do público em questão: adolescentes: pessoas em desenvolvimento, questionadores da ordem, viajantes que deixaram a condição de criança, mas ainda não alcançaram a condição de adulto.

Acerca do primeiro ponto Vasconcelos (2002) destaca que o plantão, por si só, já Serv. Soc. \& Saúde, Campinas, SP v. 12, n 1 (15), p. 83-102 jan./jun. 2013 ISSN 1676-6806 
é um campo de atuação bastante inquietador, considerado como o "[.... 'termômetro' da instituição” permitindo ao assistente social identificar quais são as necessidades expressas pelos usuários, e “[...] até que ponto suas demandas estão sendo consideradas e/ou atendidas pela unidade” (VASCONCELOS, 2002, p. 492).

O setor constitui-se ainda na “[...] única porta de qualidade imediatamente aberta ao usuário” - o que não o reduz a um balcão de informações -, onde este pode receber orientação profissional sobre a complexidade do movimento institucional e, por vezes, municipal. A mesma autora destaca o perfil do local destinado para estes serviços: “[...] em salas geralmente pequenas - em tamanho ou para comportar o número de profissionais existentes -, sem ventilação e sem condições de respeito à privacidade e sigilo profissional” (Ibid., p. 166), contrariando legislação da área.

Behring (2009), analisando as transformações recorrentes à contrarreforma do Estado, pontua os impactos nas políticas sociais e nos espaços sócio ocupacionais do assistente social, do qual destacamos as condições de trabalho e o perfil profissional esperado:

[...] convive-se com salas sem condições de sigilo, móveis antigos, ausência de equipamentos e de condições de registro, falta de manutenção, de material de consumo e de investimento em bens de capital e equipamentos. [...] disso, tem-se a tendência de uma redefinição do próprio trabalho profissional, reduzido ao plantão de emergência, à ambulância que tenta salvar as vítimas do ajuste e ao monitoramento da terceirização do trabalho desprofissionalizado [...] (BEHRING, 2009, p. 316-317).

As contribuições de Vasconcelos (2002) e Behring (2009) convergem com questões subjetivas e objetivas vivenciadas pelos profissionais do setor de Serviço Social do Pronto Atendimento Adulto. De fato, a tensão que permeia o espaço do plantão, as concepções acerca das atribuições do assistente social - tanto por parte dos usuários, como dos empregadores - aliada as precárias condições de trabalho coloca ao profissional a árdua tarefa de garantir os seus direitos.

Um desafio que não minimiza as diversas e complexas demandas apresentadas pelos usuários. Sujeitos de direitos que nos colocam o desafio de transformar o conhecimento em atos e palavras para transformar situações de privação de direitos, dor e desconhecimento. São pessoas muitas vezes divididas por necessidades, idade ou comportamentos, mas que na verdade são homens, mulheres, idosos, crianças e Serv. Soc. \& Saúde, Campinas, SP v. 12, n 1 (15), p. 83-102 jan./jun. 2013 ISSN 1676-6806 
adolescentes que se apresentam por inteiro. Aqui reside o segundo ponto para esta discussão.

Com efeito, as ações de orientação e acompanhamento aos adolescentes e seus familiares colocam para o profissional o desafio de garantir direitos e transformar regras e fluxos, em algo mais compreensível e que possa ser utilizado no cotidiano. Essa tarefa é repleta de incertezas e surpresas. Isto porque, o adolescente tanto pode acolher as orientações, refletir junto com o profissional e criar alternativas, como pode reagir de modo agressivo por considerarem que:

- As informações e orientações são desnecessárias, não encontram consonância com o seu cotidiano. E de fato em muitas situações o descumprimento da legislação social - por parte de profissionais e serviços - no atendimento aos adolescentes fazem com que a perspectiva do direito fique deturpada.

- O processo de orientação é irritante e invasivo, pois interrompem o fluxo de atendimento - o acesso direto ao médico - e busca informações familiares que para o adolescente não são relevantes.

Em ambas as situações um ponto é fato: é impossível compreender e atuar com os adolescentes desconhecendo suas “múltiplas” possibilidades.

\section{ADOLESCENTE: CONHECENDO O VIAJANTE}

Eu não caibo mais nas roupas que eu cabia. Eu não encho mais a casa de alegria. Os anos se passaram enquanto eu dormia. E quem eu queria bem me esquecia. Será que eu falei o que ninguém dizia? Será que eu escutei o que ninguém ouvia? Eu não vou me adaptar, me adaptar.

Não vou me adaptar - Titãs

Considerado um segmento em situação de vulnerabilidade - pelo ciclo de vida o adolescente é alvo de inúmeras ações que adotam como parâmetro a legislação social brasileira em vigor, bem como documentos que tratam de assuntos específicos deste público. São ações que procuram minimizar o impacto das questões que permeiam o universo juvenil. Situações, muitas vezes, incompreendidas, rotuladas e banalizadas por adultos que, não aceitam o convite - explícito ou implícito - para descobrir desafios, sonhos, lutas, alegrias e dificuldades enfrentadas por esses viajantes: os adolescentes.

Na verdade, a palavra “adolescente” extrapola as “certezas” pautadas no senso comum, as definições legais e produções cientificas, pois se "trata de uma construção Serv. Soc. \& Saúde, Campinas, SP v. 12, n 1 (15), p. 83-102 jan./jun. 2013 ISSN 1676-6806 
social” que se dá em diferentes conjunturas históricas. Neste sentido, Losacco (2007), a partir das contribuições de Bordieu (LOSACCO, 2007. In: BORDIEU, 1983, p. 3) destaca que “[...] as divisões etárias são arbitrárias [...] os cortes, seja em classes de idade ou gerações, variam inteiramente e são objeto de manipulação”, sendo que a “[...] relação entre idade social e idade biológica [...] ” é muito mais complexa do que à primeira vista pode demonstrar.

É fato que a sociedade se utiliza destes critérios, para situar este indivíduo em um determinado grupo, o que lhe atribui direitos, deveres e referência social de um grupo. Entretanto, “as idades não possuem um caráter universal” (CARRARO, 1999, apud. LOSACCO, 2009, p. 66). Sendo uma construção histórica, não é possível atribuir um valor universal para as idades, de forma a padronizá-las. Entretanto, há no senso comum a crença de que é possível obter a maturidade para as habilidades da vida adulta "naturalmente”. Não se trata de um processo, mas sim a chegada de uma data. A data em questão é o aniversário de dezoito anos. Uma inverdade que não é discutida com os adolescentes, bem como com as famílias. E famílias no plural, pois o recorte de renda não é o selo que distingue as famílias que obtém maior ou menor êxito na relação com os adolescentes. Rico ou pobre, do sexo masculino ou feminino, negro ou branco, o adolescente "requer” a colaboração da família, do Estado e da sociedade para "transpor essa passagem para a vida adulta”. Isto porque, independentemente do local onde mora, essa passagem é sempre conflituosa, acarretando “... o abandono daquelas prerrogativas especiais...”, ou “criancices” na definição dos adultos, “... substituindo-as por direitos, responsabilidades, perspectivas e satisfações que são adequadas para o “adulto”...”. (KENISTON, 1960 apud. LOSACCO, 2007, p. 67). Dizer apenas destas mudanças, pode não dar a efetiva compreensão das transformações que ocorrem com o adolescente, em termos gerais, na adolescência ou juventude:

[...] é um período filogeneticamente pré-determinado, desencadeado pela maturação neurológica, que promove mudanças significativas de ordem corporal, de apreensões cognitivas e, consequentemente, de comportamento. É um acontecimento universal que, mais cedo ou mais tarde, se instala na vida de todo o ser humano, independentemente de sua cultura, classe econômica, etnia ou sexo (LOSACCO, 2007, p. 68).

É uma fase que suscita vulnerabilidades, que serão enfrentadas com o apoio - ou não de parceiros. Parceiros que devem estar presente neste momento de "crise”, ou, da “... ruptura Serv. Soc. \& Saúde, Campinas, SP v. 12, n 1 (15), p. 83-102 jan./jun. 2013 ISSN 1676-6806 
do equilíbrio no processo biopsico-relacional adquirido na construção da infância”. O adolescente é interpelado para deixar a infância dirigir-se rumo à vida adulta. Em síntese,

O adolescente é um viajante que deixou um lugar e ainda não chegou no seguinte. Vive um intervalo entre liberdades anteriores e responsabilidades/compromissos subsequentes; vive uma última hesitação antes dos sérios compromissos da fase adulta. É um período de contradição. Confuso, ambivalente e muitas vezes doloroso (LOSACCO, 2007, p. 68-69)

Crise, desordem, contestação: palavras “temidas” pelos adultos fazem parte do universo do adolescente nesta viagem, ou síntese, em que o atual é desconstruído para dar lugar ao novo, que pode ou não ser aceito. Esse processo de construção não ocorre sem transformações, muitas vezes em momentos onde o que se quer é a tranquilidade de uma paz mesmo sem voz. Afinal, da aceitação "quase” pacífica da criança, tem-se o questionamento “às vezes autoritário” do adolescente, que ao questionar valores, normas, estruturas busca “determinar sua identidade” (LOSACCO, 2007, p. 71).

Assim, entre "não caber mais nas roupas que cabia” e já "não encher a casa de alegria” o adolescente tem o duplo desafio: se adaptar e, ao mesmo tempo, transformar a realidade onde se encontra. Uma tarefa nada fácil, sobretudo quando estão permeadas por questões econômicas, políticas, sociais e culturais de sociedades desiguais, como a brasileira. Uma sociedade que não nos permite realizar nenhuma discussão sobre a população - qualquer que seja a idade - no singular, pois é feita de fraturas, desigualdades e violações. Assim, como nos alerta o jurista Nogueria Neto:

Para falar da criança e do adolescente, no mundo e no Brasil, é necessário contextualizá-los: não se pode falar de uma única infância e adolescência, e sim de várias. Nessa linha, questiona Mullher (2002): 'se nos perguntássemos quem é a criança no Brasil hoje, necessariamente teríamos que apontar divergências entre elas, em função de diferenças substanciais entre suas realidades de vida' (NOGUEIRA NETO, 2009, p. 25).

\section{ANALISANDO OS NÚMEROS: UMA ANÁLISE QUANTI-QUALITATIVA}

O essencial é saber ver, Saber ver sem estar a pensar, Saber ver quando se vê, E nem pensar quando se vê

Nem ver quando se pensa. Fernando Pessoa, 2007

Um dos desafios presente na comunicação entre a teoria e a prática é a capacidade de "abstrair". Um movimento que exige a coragem de assumir as incertezas e incompletude do continuo processo de conhecimento. Assumindo este compromisso 
apresentamos os dados e uma avaliação do atendimento desenvolvido no setor de Serviço Social do Pronto Atendimento Adulto do município de Barueri.

Desde 2007 a Coordenação do Pronto Atendimento Adulto estabeleceu um fluxo para atender os adolescentes, em decorrência de algumas situações envolvendo este público, seus familiares e aspectos legais. Assim, acordou-se que a Ficha de Atendimento seria elaborada e o adolescente encaminhado para um Pré-Atendimento com um profissional da equipe de Enfermagem. Diante de uma situação de emergência, o adolescente seria encaminhado para atendimento e o assistente social seria comunicado. Diante de uma situação sem necessidade de atendimento imediato, o adolescente seria encaminhado ao setor de Serviço Social para diálogo, identificação do acompanhante e contato com os responsáveis. O tempo de espera para este procedimento não prejudicaria o adolescente na ordem de chamada para atendimento médico. E sob nenhuma condição o adolescente seria encaminhado para o atendimento social sem passar por uma avaliação para identificar sua demanda clínica.

A implantação deste fluxo não aconteceu sem inúmeras questões que mereceram - e merecem - a constante reflexão da equipe. Uma primeira indagação da equipe foi sobre a possibilidade de contribuir para "inviabilizar" o atendimento do adolescente. Uma direção que estaria violando a Política de Saúde e indo contra o projeto éticopolítico profissional do Serviço Social. Contudo, no desenvolvimento do fluxo, com todas as intercorrências que em muito se distanciavam da proposta inicial, a equipe identificou que o fluxo colaborou para que os profissionais tivessem contato com estes adolescentes, um segmento então desconhecido, salvo em situações esporádicas de internação nas quais os responsáveis solicitavam a presença do assistente social ou deixavam os adolescentes sem acompanhante e então a equipe de enfermagem solicitava a presença do profissional “pois se tratava de um caso social”.

Tomamos como referência de análise os dados do ano de 2009. Neste o ano a equipe realizou 9.117 atendimentos gerais e 1.515 atendimentos para crianças e adolescentes. A partir do Livro de Registro Técnico realizamos o levantamento de 764 atendimentos - 50,43\% do atendimento anual - considerando as seguintes informações organizadas em dois blocos: $1^{\circ}$ ) setor, sexo, idade, município, complexidade: essas informações são anotadas pelos profissionais; $2^{\circ}$ ) atendimento médico, acompanhante, encaminhamento e contato com Conselho Tutelar: são informações que podem constar Serv. Soc. \& Saúde, Campinas, SP v. 12, n 1 (15), p. 83-102 jan./jun. 2013 ISSN 1676-6806 
no relato da situação.

As intervenções com adolescentes neste período representaram 16,62\% do total de atendimentos realizados pelas técnicas do setor. Neste sentido, ganham destaque também, as condições objetivas para o trabalho profissional, como a sala destinada para o atendimento profissional. Um espaço que não possibilita um atendimento tranquilo e sigiloso, para que o adolescente e seu acompanhante se sintam - efetivamente - em condições de dialogar, sobretudo nas situações de "violação de direitos" e "violências".

Diante da impossibilidade de dispor de um local mais adequado para a atuação, a despeito da solicitação a equipe utiliza como estratégia, o revezamento entre as técnicas, ou seja, uma profissional atende do lado de fora permitindo o atendimento de “porta fechada”, nas situações onde se identifica a necessidade.

Considerando os limites apresentados, as possibilidades para socializar informações são complexas, mas não impossível. E um ator que colabora para esta contradição é o próprio adolescente. Estes, em algumas situações, permitem o atendimento coletivo, iniciam um diálogo divertido, por vezes carinhoso, e possibilita que a intervenção obtenha uma dimensão educativa, reflexiva para si, e para os demais presentes. É fato que a postura e direção adotada pelo profissional têm um grande peso. Assim, entendemos que os números de atendimento são expressivos - típicos de um serviço de urgência e emergência -, mas não permitem alcançar algumas variáveis, como:

- Os atendimentos para os adolescentes acontecem concomitantemente a outras situações. Por este motivo, em muitas situações as profissionais não conseguem acompanhar o desenvolvimento do atendimento.

- A falta de reconhecimento - por parte das equipes - de que o serviço pode fomentar ações educativas. Os serviços de urgência e emergência, funcionando como uma “porta de entrada para o sistema de saúde” pode constituir-se na porta de acesso aos demais direitos sociais.

Uma perspectiva possível, sobretudo quando identificamos a origem destes adolescentes. Um importante percentual de adolescentes que são atendidos no setor é munícipe de Barueri (62,57\%) seguido dos adolescentes de Carapicuíba (22,38\%) e em terceiro lugar encontramos o município de Itapevi (4,06\%).

Todavia, além de não explorar outras possibilidades há que se indagar quanto a aceitação e resultados do fluxo para atendimento aos adolescentes. Isto porque, considerando o fato do fluxo ter sido proposto em 2007, ou seja, em 2009 completou Serv. Soc. \& Saúde, Campinas, SP v. 12, n 1 (15), p. 83-102 jan./jun. 2013 ISSN 1676-6806 
dois anos, podemos também nos indagar sobre qual a adesão a este fluxo por parte do serviço e dos adolescentes munícipes de Barueri - até aquele momento -, uma vez que o contato com o profissional significava a ausência dos responsáveis legais.

Segundo nossa avaliação o motivo não pode ser explicado apenas pelo fato dos responsáveis legais estarem trabalhando. Essas situações ocorrem, mas não é a mais expressiva. Assim, apontamos algumas hipóteses - não verificadas - como:

- O fluxo não foi reconhecido como importante para a maioria dos adolescentes e seus responsáveis legais.

- A falta de um rigor no cumprimento do fluxo por parte das demais equipes. Muitas situações de conflito emergem por parte dos adolescentes e acompanhantes pelo fato de já terem sido atendidos no serviço sem "a burocracia de passar com a assistente social”. Ou seja, em algum momento o fluxo não foi cumprido.

- A falta de articulação entre os serviços de saúde. A partir de uma pesquisa identificamos que o Pronto Atendimento Adulto - até aquele momento - era o único serviço no município com este tipo de atendimento. Isso fazia com que os adolescentes e acompanhantes - com razão - questionassem a viabilidade do fluxo.

Quanto ao atendimento procurado, podemos observar que a maior procura é pelo atendimento clínico (65,49\% no total), ou seja, não são situações de emergência, imprevisíveis, na sua maioria os sintomas não requerem ações de urgência. Outra informação é que também no setor o número de adolescente do sexo masculino (25,65\%) atendidos é inferior comparado com o universo feminino (74,35\%). Um dado que se repete no público nos serviços de saúde, em diferentes faixas etárias.

Considerando o expressivo percentual de adolescentes atendidos - o que significa a ausência dos responsáveis legais - uma indagação que emerge é: Se os adolescentes não procuram os serviços de saúde com os seus responsáveis legais, então quem são os seus acompanhantes? A Tabela 1 nos traz importantes informações. Primeiramente o expressivo número de situações em que não consta esta informação no Livro de Registro Técnico (54,1\% no caso masculino e 48,9\% no caso feminino). Entendemos que esta lacuna convida as assistentes sociais a refletirem sobre a forma como o registro está sendo realizado, pois há situações em que o adolescente deixa o Serv. Soc. \& Saúde, Campinas, SP v. 12, n 1 (15), p. 83-102 jan./jun. 2013 ISSN 1676-6806 
serviço sem atendimento e não sabemos dizer quem o acompanhava naquele momento. Ou mesmo na situação em que o adolescente foi liberado não é possível identificar quem o acompanhava, dando margem para dúvidas quanto a efetiva possibilidade de socializar as devidas e necessárias informações acerca do fluxo, direitos e deveres dos adolescentes e familiares.

O segundo ponto diz respeito ao número de adolescentes do sexo feminino acompanhadas pelos namorados ou companheiros (17,3\%). Trata-se de uma situação complicada, sobretudo quando estes são adultos com diferenças acentuadas de idade. Nestas relações os genitores muitas vezes acreditam que já não tem nenhuma responsabilidade com a adolescente - por estas já iniciarem a vida sexual e/ou já serem mães - e estas, por sua vez, também acreditam que já respondem por si, ou ainda, o companheiro entende que é o responsável. Neste sentido, apontamos duas questões:

- Muitas adolescentes iniciam a família precocemente, sem o respaldo da família de origem, somando-se a crença de que a família do companheiro - ou este mesmo - poderá suprir todas as necessidades da adolescente.

- É expressivo o número de adolescentes que demonstram desconhecimento e certa imaturidade, acerca das questões que envolvem o início da vida sexual.

Tabela 1: Acompanhante dos Adolescentes por sexo

\begin{tabular}{l|c|c|c|c}
\hline \multirow{2}{*}{\multicolumn{1}{c|}{ Acompanhantes }} & \multicolumn{2}{|c|}{ Masculino } & \multicolumn{2}{c}{ Feminino } \\
\cline { 2 - 5 } & $\mathbf{N}^{\mathbf{o}}$ & $\mathbf{\%}$ & $\mathbf{N}^{\mathbf{0}}$ & $\%$ \\
\hline Parentes & 36 & 18,4 & 87 & 15,3 \\
\hline Amigos & 17 & 8,7 & 31 & 5,5 \\
\hline Companheiro & 3 & 1,5 & 17 & 3,0 \\
\hline Namorado & 2 & 1,0 & 81 & 14,3 \\
\hline Sozinho & 17 & 8,7 & 37 & 6,5 \\
\hline Sem Informação & 106 & 54,1 & 278 & 48,9 \\
\hline Outros & 15 & 7,7 & 37 & 6,5 \\
\hline TOTAL & $\mathbf{1 . 5 8 7}$ & $\mathbf{1 0 0}$ & $\mathbf{1 . 7 4 0}$ & $\mathbf{1 0 0}$ \\
\hline
\end{tabular}

Fonte: Tabela elaborada pela autora a partir de dados do setor de Serviço Social do Pronto Atendimento Adulto.

Reconhecendo essas questões na intervenção profissional a proposta não é apenas garantir o atendimento com o responsável legal, mas sim, dialogar com a adolescente, por vezes com o acompanhante, sobre os impactos da gestação para adolescentes e articular os atendimentos necessários para além do serviço de urgência e 
emergência. A direção é garantir o acesso às informações que possam fomentar uma reflexão crítica - não fatalista - sobre aquele momento. Também, pontuamos o número de adolescentes - do sexo feminino - que procuram o serviço de ginecologia para identificar uma "possível gravidez”, portanto, não comparecem acompanhadas de seus pais ou responsáveis, mas sim com os namorados ou “maridos” - como são identificados os companheiros. Outras estão gestantes, os genitores residem em outra cidade ou Estado e a única pessoa de contato é o namorado, e por vezes, a família deste.

São situações que exigem cuidados, pois entre inviabilizar o acesso e colaborar para que a adolescente permaneça em uma situação de violência existe um limite tênue que requer investigação. Precisamos ter o olhar investigativo para compreender que aquela situação é apenas uma parte, fragmentada, que se não olharmos com atenção ela será apenas tratada no âmbito da saúde. Em outros termos, a adolescente é atendida, vai embora e a rede social não é acionada, por conseguinte, importantes intervenções não são realizadas. O trabalho fica mais fácil, entretanto, incompleto uma vez que a possibilidade de garantir o atendimento integral não foi realizada. Um atendimento social que não pode inviabilizar o atendimento médico.

Um terceiro ponto diz respeito ao atendimento prestado ao adolescente do sexo masculino. Como demonstra a Tabela 1 estes, diferente das “meninas”, comparece sem acompanhantes $(8,7 \%)$ ou com parentes $(18,4 \%)$. As situações mais comuns são adolescentes que deixam suas cidades de origem à procura de trabalho "na cidade" sendo acolhido por familiares. Nestas situações as informações versam sobre os direitos de trabalho e as particularidades que devem ser cumpridas no atendimento ao público infanto-juvenil. Não é raro o adolescente exercer funções que ferem a legislação e colocam em risco sua vida.

Um ponto comum para os dois segmentos diz respeito a responsabilidade da família com este adolescente, independentemente do local onde esteja. Não raras vezes os responsáveis entendem que a despeito da enfermidade apresentada - de urgência ou não - o adolescente é capaz de decidir por si, ou ainda, que qualquer pessoa pode fazer isso. Não se trata apenas do atendimento médico, o adolescente se torna responsável "pela sua vida”. Os limites para refletir com os adolescentes e seus pais sobre a legislação, e assim, sobre a responsabilidade da família, do Estado e da sociedade para o desenvolvimento destes adolescentes não são poucos. Afinal, em tantas outras situações Serv. Soc. \& Saúde, Campinas, SP v. 12, n 1 (15), p. 83-102 jan./jun. 2013 ISSN 1676-6806 
- na saúde e educação - o adolescente não "precisou dos pais” por que em um "serviço de emergência” é preciso “tudo isso”?

Por outro lado, há situações em que os responsáveis legais entendem que o fluxo é correto. Acredita que essa ação dá credibilidade ao serviço, demonstra compromisso com o atendimento e permite ao responsável "reafirmar" junto ao adolescente sua responsabilidade legal. Também, ocorreram situações em que os adolescentes sobretudo meninas - haviam "fugido" de suas residências, o contato com os responsáveis além de identificar essas situações viabilizou o diálogo e resolução amigável da situação.

Outra indagação - que consideramos - pertinente é identificar quantos adolescentes obtiveram o atendimento médico após a intervenção do assistente social. Entretanto, esta informação não consta nos livros de registro (72\%). O percentual de informação registrada é pequeno (18\%) e se refere as situações onde a intervenção profissional foi mais complexa, exigindo do assistente social o acompanhamento de todas as etapas, ou pelo menos, até o adolescente ser liberado para medicação. Ainda ganha destaque a presença dos Conselheiros Tutelares nestas situações. Motivo pelo qual é possível confirmar a efetivação do atendimento médico.

Como já pontuamos a rotina e número de demandas faz com que o profissional atenda mais de uma situação, concomitantemente, o que limita as possibilidades de acompanhar o desenvolvimento das intervenções. Uma lacuna de difícil superação diante, sobretudo, do reduzido número de profissionais que atuam no setor, bem como, pelo fato de que mesmo sendo priorizado, o atendimento aos adolescentes aguarda a chamada para o atendimento médico, que pode demorar até seis horas. A impossibilidade de espera é um dos motivos que leva o adolescente a deixar o serviço sem atendimento, ao lado da evasão no momento da abordagem com a assistente social (10\%).

Ainda, procuramos apresentar um panorama da complexidade dos atendimentos realizados. Cabe esclarecer que para todos os atendimentos realizados e registrados no Livro de Atendimento Técnico as profissionais anotam o grau de complexidade que varia de I a IV, sendo; I) para intervenções simples e pontuais, II) para situações que demandam certo tempo de intervenção, III) grau que expressa situações mais complexas, que demandam encaminhamentos, contatos e um maior tempo de intervenção, e, IV) para situações muito complexas que demanda contatos, encaminhamentos, envolvem profissionais de outras áreas e/ou serviços e Serv. Soc. \& Saúde, Campinas, SP v. 12, n 1 (15), p. 83-102 jan./jun. 2013 ISSN 1676-6806 
acompanhamento. Esta classificação ocorre também no atendimento para adolescentes. Assim, identificamos que os atendimentos com a complexidade II se destacam $(58,64)$. Nestes casos, é comum o contato com os genitores e a liberação do atendimento sem maiores intervenções. As intervenções que são classificadas com uma maior complexidade a IV, não são tão expressivas numericamente (13,35\%).

Entretanto, são nestas situações que o profissional encontra mais obstáculos para efetivar uma ação socioeducativa, pois estas carregam uma gama de questões, muitas vezes de difícil articulação nos limites de um serviço de urgência e emergência, especialmente, pelas características do setor, do serviço e do município, como apresentado neste item.

\section{CONSIDERAÇÕES FINAIS}

A atuação profissional nos serviços de saúde tem o desafio de considerar o processo "saúde e doença” como resultado de determinantes sociais e assim, reconhecer os usuários como sujeitos de direitos. Sujeitos que apresentam suas demandas "por inteiro” e não segmentadas por "políticas sociais”, por profissionais de referência localizados em diferentes serviços.

Não ignoramos as condições concretas de trabalho, nos diferentes espaços sócioocupacionais. Estamos inseridos em um destes espaços e sabemos dos impactos de atuar em salas que não garantem o sigilo profissional, de não ter a colaboração para garantir o aprimoramento profissional, entre outras questões. Sabemos o quanto é difícil garantir a comunicação com alguns profissionais e/ou serviços no sentido de não "fragmentar” as demandas apresentadas pelos usuários, na típica frase: “Senhor isso não é aqui!” ou então “isso eu trato aqui, o resto você deve procurar em tal lugar”. São situações recorrentes nos serviços de saúde, evidenciando a falta de articulação entre as políticas sociais. E afirmarmos que esta fragilidade na comunicação com os serviços de assistência social no âmbito municipal é gritante e muito prejudicial aos usuários atendidos no setor, inclusive os adolescentes.

Entretanto, entendemos que a clareza dos obstáculos não é o fim último do processo de investigação, antes, a clareza das condições objetivas devem subsidiar intervenções no sentido de alterar esta realidade e superar os obstáculos identificados, 
limites e possibilidades fazem parte do processo. Neste sentido ao tomarmos como objeto de estudo a atuação profissional com os adolescentes em um serviço de saúde de urgência e emergência - conseguimos identificar aspectos da abordagem, orientação e encaminhamentos até então ignorados. Reconhecer as possibilidades não exploradas, os avanços não considerados, mas também, os desafios superados, as conquistas, os acertos.

Para findarmos, entendemos que um desafio está colocado para as profissionais que atuam no setor: transitar entre as possibilidades de efetivar ações socioeducativas em uma perspectiva emancipatória, ou limitar-se a ações pontuais e/ou manipuladoras. O limite entre essas duas possibilidades é tênue e não nos é possível dizer que a ação é desenvolvida somente em uma ou outra direção. Acreditamos que esta é a maior descoberta desta investigação: reconhecer que estamos sujeitos a desenvolver práticas burocráticas que se distanciam de uma dimensão educativa emancipatória. Estamos sujeitos a nos limitar a informar, a tratar o adolescente "como um problema” a mais no universo do tumultuado cotidiano do serviço de emergência.

Corremos o risco de “desinformar”, de fragmentar o atendimento “aquela situação pontual” e não reconhecer "naquela partícula” a necessidade de uma intervenção articulada, mais demorada. Os possíveis motivos foram explicitados, mas não minimizam o compromisso profissional para sua superação. Na verdade, o reconhecimento de que estas questões interferem na direção profissional é tão importante quanto desenvolver ações para sua solução.

Assim, identificamos que as profissionais - em alguns momentos - conseguem fazer do fluxo uma estratégia para socializar informações com os adolescentes e familiares, na perspectiva da consolidação e ampliação da cidadania. Uma perspectiva que se expressa no movimento reflexivo acerca de temas diversos como: sexualidade, direitos dos adolescentes, deveres do adolescentes, família, estudo, trabalho e estratégias para concretização do direito à saúde, inclusive nos serviços de emergência. Tal intervenção não se limita a informar "profissionalmente” o instituído legalmente. Antes, pressupõe-se que os usuários possam usufruir “[...] de todo conhecimento socialmente produzido, especialmente daqueles gerados no campo da ciência e da tecnologia [...]”, de modo que sejam compreensivas, para que os usuários dele façam uso nos diferentes momentos da sua vida.

Entretanto, identificamos lacunas no fluxo que não podem ser ignoradas, como: a falta de informações acerca dos acompanhantes dos adolescentes atendidos; a falta de Serv. Soc. \& Saúde, Campinas, SP v. 12, n 1 (15), p. 83-102 jan./jun. 2013 ISSN 1676-6806 
informação sobre o desenvolvimento da situação (o adolescente passou ou não em consulta médica); e, quais as estratégias seriam possíveis para socializar com os demais serviços municipais o fluxo implantado e discutir as possíveis adaptações e/ou alteração.

O processo que iniciamos para conhecer o viajante - adolescente - nos permitiu nos conhecer e reconhecer os limites e possibilidades para uma proposta educativa.

\section{REFERÊNCIAS}

ABREU, M. M. Serviço Social e a organização da cultura: perfis pedagógicos da prática profissional. São Paulo: Cortez, 2002.

BEHRING, E. Política Social no contexto da crise capitalista. III Unidade: Produção e reprodução da vida social. Brasília: Programa de Capacitação Continuada para Assistentes Sociais. Brasília: CFESS / ABEPSS /CEAD-UnB, 2009.

BOSCHETTI, I. Seguridade social no Brasil: conquistas e limites à sua efetivação. III Unidade: Produção e reprodução da vida social. Brasília: Programa de Capacitação Continuada para Assistentes Sociais. Brasília: CFESS / ABEPSS /CEAD-UnB, 2009. IAMAMOTO, M. V. O Serviço Social na cena contemporânea. I Unidade: O significado sócio-histórico das transformações da sociedade contemporânea. Programa de Capacitação Continuada para Assistentes Sociais. Brasília: CFESS / ABEPSS /CEAD-UnB, 2009.

IAMAMOTO, M. V. O Serviço Social na Contemporaneidade: trabalho e formação profissional. 10a ed., São Paulo: Cortez, 2006.

IAMAMOTO, M. V. Os espaços sócio-ocupacionais do assistente social. IV Unidade: O significado sócio-histórico das transformações da sociedade contemporânea. Programa de Capacitação Continuada para Assistentes Sociais. Brasília: CFESS / ABEPSS /CEAD-UnB, 2009a.

IAMAMOTO, M. V. Serviço Social em Tempo de Capital Fetiche: capital financeiro, trabalho e questão social. São Paulo: Cortez, 2007.

LOSACCO, S. O jovem e o contexto familiar. In: ACOSTA, A.R.; VITALE, M. A. Família: redes, laços e políticas públicas. São Paulo, IEE-PUCSP e Cortez Editora, 2007 ( $3^{\mathrm{a}} \mathrm{Ed}$.).

Serv. Soc. \& Saúde, Campinas, SP v. 12, n 1 (15), p. 83-102 jan./jun. 2013 ISSN 1676-6806 
MIOTO, R. C. T. Orientação e acompanhamento de indivíduos, grupos e famílias acumulação, trabalho e desigualdades. V Unidade: Produção e reprodução da vida social. Programa de Capacitação Continuada para Assistentes Sociais. Brasília: CFESS / ABEPSS /CEAD-UnB, 2009.

NOGUEIRA NETO, W. Por um sistema de promoção e proteção dos direitos humanos de crianças e adolescentes. Serviço Social \& Sociedade. São Paulo: Cortez, ano XXVI, n 83, p. 5-29, mês setembro, 2005.

PESSOA, Fernando. Poemas Completos de Alberto Caeiro. Ed. Martin Claret, 2007.

SARTI ACOSTA, A. R. e VITALE, M. A. Família: redes, laços e políticas públicas. São Paulo, IEE-PUCSP e Cortez Editora, 2007 (3 ${ }^{\text {a }}$ Ed.) 2009

SCHWARTZMAN, S. Os desafios da educação no Brasil. In: BROCK, C., SCHWARTZMAN, S. (Org). Os desafios da educação no Brasil. Rio de Janeiro: Nova Fronteira, 2005a. Disponível em: http://www.schwartzman.org.br/simon/desafios/1desafios.pdf. Acesso em: 17/08/2010. SCHWARTZMAN, S. Trabalho infantil no Brasil. Brasília: OIT, 2001. Disponível em http://www.oitbrasil.org.br/info/downloadfile.php?fileId=56. Acesso em 10/08/2010.

YAZBEK, M. C. Fundamentos históricos e teórico-metodológicos do Serviço Social. Unidade II: O Serviço Social no contexto das transformações societárias. Programa de Capacitação Continuada para Assistentes Sociais. Brasília: CFESS / ABEPSS / CEAD-UnB, 2009a.

YAZBEK, M. C. O significado sócio histórico da profissão. Unidade II: O Serviço Social no contexto das transformações societárias. Programa de Capacitação Continuada para Assistentes Sociais. Brasília: CFESS / ABEPSS /CEAD-UnB, 2009. 